DOI: $10.12731 / 2306-1561-2013-4-2$

\title{
EQUIPMENT FOR PRODUCE DRY CONSTRUCTION MIXTURES
}

\section{Wai Phyo Aung}

\section{Abstract}

This article analyzes the current state of development of dry construction mixtures. The basic advantages of dry mixes and a classification of dry mixes. Briefly describes the technological process of production of dry mixes and is a model of a software implementation of the automated process control of production of dry construction mixes.

Keywords: dry construction mixtures, process automation and production, control system, software, automated management.

\section{УДК 691.5}

\section{ОБОРУДОВАНИЕ ДЛЯ ПРОИЗВОДСТВА СУХИХ СТРОИТЕЛЬНЫХ СМЕСЕЙ}

\section{Вэй Пьо Аунг}

\section{Аннотация}

В статье анализируется современное состояние развития производства сухих строительных смесей. Показаны основные преимущества сухих строительных смесей и приведена классификация сухих строительных смесей. Кратко описан технологический прочесс производства сухих строительных смесей и приведен макет программной реализачии системы автоматизированного управления процессами производства сухих строительных смесей.

Ключевые слова: сухие строчтельные смеси, автоматизация технологических процессов и производств, АСУ ТП, программное обеспечение, автоматизированное управление.

Сухие строительные смеси представляют собой специальный набор ингредиентов, приготовленный в заводских условиях в строгом соответствии с рецептурой для выполнения определенного вида строительных и ремонтных работ [1, $3,6]$. Как правило, в состав сухой смеси входит вяжущее вещество (сочетание цемента и извести, гипса и извести или другие комбинации). Кроме того, в сухие смеси включены нейтральные наполнители для обеспечения оптимального объема (песок) и специальные модифицирующие добавки, придающие смеси необходимые свойства (морозоустойчивость, устойчивость к высоким температурам, воздухо- и водостойкость и т.п.) [1 - 6]. Помимо всего прочего, в состав сухих строительных смесей добавляются 
компоненты, предотвращающие грибковое поражение отделочных материалов, придающие составам удобоукладываемость, пластичность, адгезионные свойства, а покрытиям - твердость, цвет, гидрофобность.

Ассортимент строительных смесей включает:

- вяжущие материалы (цемент, гипс, известь, алебастр);

- универсальные смеси;

- гидроизоляция;

- грунтовки (грунт);

- затирки для швов (затирочная смесь, расшивка, заделка стыков, другие клеевые сухие смеси, например, гипсокартон);

- клеи (сухие клеевые смеси, универсальные, строительные, плиточные);

- наливной пол (смеси для пола, ровнители, стяжка);

- шпатлевки;

- штукатурки.

Сухие строительные смеси на сегодняшний момент являются наиболее динамично развивающимся направлением в строительстве. В отличие от обычных смесей, время приготовления рабочего раствора, благодаря их порционному заводскому приготовлению, сокращается в несколько раз. Так же существенно понижается уровень расходов материалов и в тоже время из-за пластичности сухих смесей повышается производительность труда. Типовой состав технологичечкой линии по производству сухих строительных смесей представлен на рисунке 1 [3].

Смесители - предназначены для интенсивного смешения сыпучих компонентов. Такие аппараты позволяют производить смеси сложного состава при продолжительности одного цикла от 2,5 до 5 минут. Кроме того, они могут оснащаться высокоскоростными ножевыми дробилками, задача которых диспергировать компоненты смесей.

Фасовочная машина - предназначена для фасовки сыпучих продуктов различного состава (от тонкодисперсных до зернистых). Также такие машины могут применяться и для упаковки сухих шпатлевок, клеев и для сухого бетона. Производительность фасовочных машин зависит от свойств фасуемого продукта и емкости мешков и может составлять несколько сот мешков в час.

Дозирование добавок - может происходить как автоматически (с помощью автоматических дозаторов добавок), так и вручную, с помощью предварительно взвешенной порции добавок в специальных воронках, оборудованных затвором. В нужный момент (согласно технологического процесса производства той или иной строительной сухой смеси) затвор открывается либо автоматически, либо вручную оператором.

Устройства по распаковке мешков - различные компоненты, входящие в состав строительных сухих смесей, обычно поступают в упакованном виде. Распаковочные устройства представляют собой воронку, которая оборудована решеткой и рукавным 
фильтром. Мешки на решетке вспарываются вручную оператором, а запыленный воздух втягивается через фильтр и очищается.
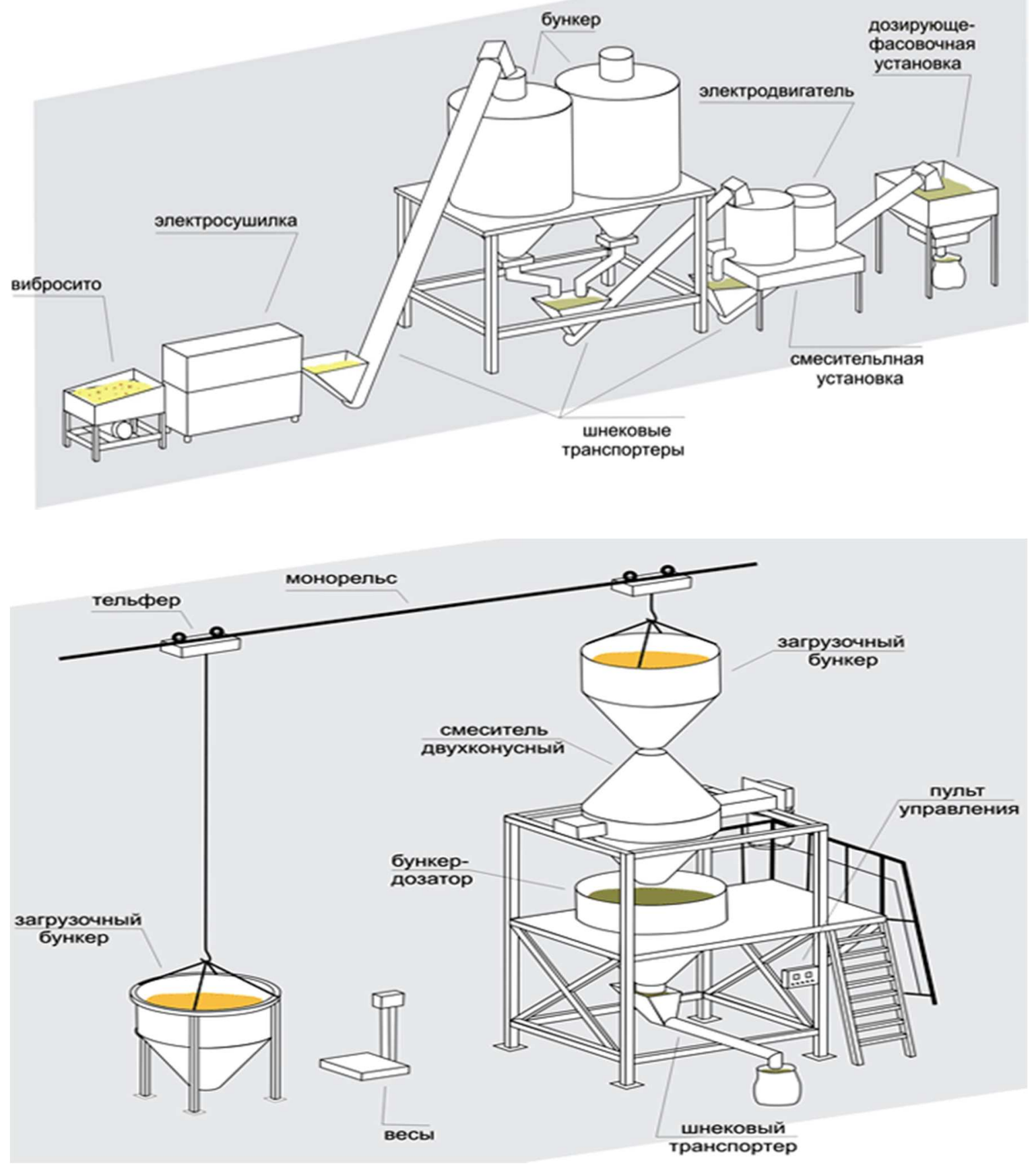

\section{Рисунок 1 - Технологическая линия производства сухих строительных смесей}

Приготовление бетонных смесей осуществляется на механизированных и автоматизированных районных и центральных заводах и на строительных площадках. 


\section{Список информационных источников}

[1] Вэй Пьо Аунг Краткий обзор современного состояния развития производства сухих строительных смесей // Автоматизация и управление в технических системах. - 2012. - № 1; URL: auts.esrae.ru/1-2 (дата обращения: 22.09.2013).

[2] Вэй Пьо Аунг, Остроух А.В. АСУТП производства сухих строительных смесей // Автоматизация и управление в технических системах. - 2013. - № 1(3); URL: auts.esrae.ru/3-52 (дата обращения: 22.09.2013).

[3] Вэй Пьо Аунг, Остроух А.В. Автоматизированная система управления технологическим процессом производства сухих строительных смесей // Автоматизация и управление в технических системах. - 2013. - № 2(4); URL: auts.esrae.ru/4-120 (дата обращения: 25.10.2013).

[4] Остроух А.В., Вэй Пьо Аунг, Мьо Лин Аунг, Исмоилов М.И. Обзор современного состояния развития автоматизации производства сухих строительных смесей // В мире научных открытий. Серия «Проблемы науки и образования». - 2012. - №12. C.12-19.

[5] Остроух, А.В. Информационные технологии в научной и производственной деятельности / [ред. А.В. Остроух] - М: ООО "Техполиграфцентр", 2011. - 240 с. ISBN 978-5-94385-056-1.

[6] Тянь Юань. Мониторинг процесса производства сухих строительных смесей / А.В. Остроух, Вэй Пьо Аунг, Юань Тянь // Наука и образование в XXI веке: Теоретические и прикладные вопросы науки и образования: сб. науч. тр. по матлам Междунар. науч. - практ. конф. 30 сентября 2013 г.: Часть 1. - Тамбов: ТРОО «Бизнес-Наука-Общество», 2013. - С. 138-140. 